\author{
J. $\mathrm{LIU}^{1, \infty}$ \\ U.A. GLASMACHER ${ }^{2}$ \\ M. $\mathrm{LANG}^{3, *}$ \\ C. TRAUTMANN ${ }^{3}$ \\ K.-O. $\operatorname{VOSS}^{3}$ \\ R. NEUMANN ${ }^{3}$ \\ G.A. WAGNER ${ }^{4}$ \\ R. MILETICH
}

\section{Raman spectroscopy of apatite irradiated with swift heavy ions with and without simultaneous exertion of high pressure}

\author{
${ }^{1}$ Institute of Modern Physics (IMP), Chinese Academy of Sciences, Lanzhou 730000, P.R. China \\ ${ }^{2}$ Geologisch-Paläontologisches Institut (GPI), Ruprecht-Karls-Universität, Heidelberg, Germany \\ ${ }^{3}$ Gesellschaft für Schwerionenforschung (GSI), Darmstadt, Germany \\ ${ }^{4}$ Max-Planck-Institut für Kernphysik (MPI), Heidelberg, Germany \\ ${ }^{5}$ Mineralogisches Institut (MI), Ruprecht-Karls-Universität, Heidelberg, Germany
}

\begin{abstract}
Received: 10 December 2007/Accepted: 4 January 2008
Published online: 22 January 2008 • C Springer-Verlag 2008

ABSTRACT Durango apatite was irradiated with energetic $\mathrm{U}$ ions of $2.64 \mathrm{GeV}$ and $\mathrm{Kr}$ ions of $2.1 \mathrm{GeV}$, with and without simultaneous exposure to a pressure of $10.5 \mathrm{GPa}$. Analysis by confocal Raman spectroscopy gives evidence of vibrational changes being marginal for fluences below $5 \times 10^{11}$ ions $/ \mathrm{cm}^{2}$ but becoming dominant when increasing the fluence to $8 \times 10^{12}$ ions $/ \mathrm{cm}^{2}$. Samples irradiated with $\mathrm{U}$ ions experience severe strain resulting in crystal cracking and finally breakage at high fluences. These radiation effects are directly linked to the formation of amorphous tracks and the fraction of amorphized material increasing with fluence. Raman spectroscopy of pressurized irradiated samples shows small shifts of the band positions with decreasing pressure but without a significant change of the Grüneisen parameter. Compared to irradiations at ambient conditions, the Raman spectra of apatite irradiated at $10.5 \mathrm{GPa}$ exhibit fewer modifications, suggesting a higher radiation stability of the lattice by the pressure applied.
\end{abstract}

PACS 61.80.Jh; 62.50.+p; 07.35.+k

1

\section{Introduction}

Spontaneous fission of ${ }^{238} \mathrm{U}$ in natural minerals leads to a continuous production of particle tracks on a geological time scale and can be used to calculate the time that elapsed since the onset of track accumulation. Durango apatite, containing trace amounts of uranium isotopes, has been employed as an age-dating standard in fission-track laboratories all over the world $[1,2]$. Additionally, materials belonging to the class of apatites have been studied as nuclear-waste containment matrices due to their crystal-chemical adaptation, non-stoichiometry, and ability of increasing the density of cation acceptor sites [3]. In these cases, apatite materials are exposed to radiation environments. Since energetic heavy ions from an ac- celerator produce damage trails similar to fission tracks, they are a suitable tool to mimic fission tracks in minerals under pressure and temperature conditions similar to those occurring in nature. Based on this premise, we chose Durango apatite from Mexico for studies involving heavy-ion irradiation and high pressure.

In previous studies of natural apatite, radiation damage and thermal annealing effects were quantified by investigating ion track damage with channeling Rutherford backscattering spectrometry (CRBS) [4] and transmission electron microscopy (TEM) [5]. Using TEM, the average widths of fission tracks were found to be $9 \mathrm{~nm}$ parallel and $5 \mathrm{~nm}$ perpendicular to the crystal $c$ axis, respectively [6]. The radius of ion tracks generally increases with increasing electronic

\footnotetext{
Fax: +86-931-8272100, E-mail: j.liu@impcas.ac.cn

* Present address: Department of Geological Sciences, University of Michigan, Ann Arbor, USA
}

energy loss $(\mathrm{d} E / \mathrm{d} x)$ of the ions. For tracks produced with $\mathrm{U}$ ions $(\mathrm{d} E / \mathrm{d} x=$ $17.5 \mathrm{keV} / \mathrm{nm}$ ) a mean diameter of about $10 \mathrm{~nm}$ was measured [7], whereas tracks of $30-\mathrm{MeV} \mathrm{C}_{60}$ cluster projectiles exhibited cross sections of varying shapes and with diameters between 8 and $16 \mathrm{~nm}$ [8]. In addition, ion-induced damage and correlated stress were studied by X-ray diffraction (XRD), also revealing an anisotropic response to the damage process [9].

Tracks annealed at elevated temperatures shrink in length and decay into damage segments interconnected by partially reconstructed lattice regions. Because the thermal history of geological samples has a significant impact on dating, extensive track annealing experiments have been performed under various temperature and time conditions. In contrast, the relevance of pressure on track formation is more difficult to access. Structural changes of pressurized non-irradiated apatite samples were examined with Raman spectroscopy displaying phase stability up to $25 \mathrm{GPa}$ at room temperature (RT) [10]. Exposure to pressures above $12 \mathrm{GPa}$ and simultaneously to temperatures up to $2300^{\circ} \mathrm{C}$ created the $\gamma-\mathrm{Ca}_{3}\left(\mathrm{PO}_{4}\right)_{2}$ phase, which is stable only at high pressure [11].

The question of whether fissiontrack generation is possibly influenced by the presence of high pressure can now be tackled by laboratory radiation experiments. In a recent novel approach, pressure was included as a parameter by squeezing a small zircon sample between two diamond anvils at RT, and irradiating it with energetic ion projectiles. The simultaneous exposure to 
a pressure of $14 \mathrm{GPa}$ and to energetic $\mathrm{U}$ ions $(24.5 \mathrm{keV} / \mathrm{nm})$ was shown to trigger the transformation of zircon into its metastable phase reidite at a much lower pressure than without ion irradiation [12]. Tracks in zircon and their annealing behavior are also of interest for dating and have been examined systematically by XRD and Raman spectroscopy $[13,14]$.

In this study, the damage evolution in apatite was analyzed as a function of irradiation fluence and external pressure. We present new results based on Raman spectroscopy of single crystals that were ion irradiated at RT (1) in vacuum, (2) at ambient pressure, and (3) at simultaneous exposure to high pressure. The response of apatite to ion irradiation under external pressure is of interest not only in geosciences but also in materials science.

\section{$2 \quad$ Experimental}

As material we used several transparent, inclusion-free single crystals of Durango apatite from Mexico $\left(\mathrm{Ca}_{5}\left(\mathrm{PO}_{4}\right)_{3}(\mathrm{OH}, \mathrm{F}, \mathrm{Cl})\right)$ of mass density $\sim 3.2 \mathrm{~g} / \mathrm{cm}^{3}$ and hexagonal $\mathrm{P}_{3} / m$ structure. Prior to ion irradiation, all samples were annealed at $430^{\circ} \mathrm{C}$ for $24 \mathrm{~h}$ in order to eliminate existing tracks from spontaneous nuclear fission (samples prepared in this way are denoted throughout this paper as "non-irradiated'). The irradiation experiments were performed at RT and under beam incidence normal to the $c$ axis of the crystal. Irradiations without external pressure were carried at the UNILAC linear accelerator of GSI using $\mathrm{U}$ ions of $11.4 \mathrm{MeV} / \mathrm{u}$. The initial beam energy is reduced to $11.1 \mathrm{MeV} / \mathrm{u}$ at the sample surface because the ions first passed through three aluminum foils (total thickness $\sim 3 \mu \mathrm{m}$ ) serving for fluence on-line control. The fluence applied varied between $1 \times 10^{10}$ and $8 \times 10^{12}$ ions $/ \mathrm{cm}^{2}$ (Table 1 ).

For the pressure experiment, a smallsized sample ( $\sim 80 \mu \mathrm{m}$ in diameter) was mounted in a Merrill-Bassett type diamond anvil cell (DAC). A 4:1 mixture of methanol and ethanol served as pressure-transmitting medium, and the pressure in the DAC was monitored via ruby fluorescence with an uncertainty of $\sim 0.5 \mathrm{GPa}$. The sample pressurized to $10.5 \mathrm{GPa}$ was ir-

\begin{tabular}{lcccccc}
\hline Ion & $\begin{array}{c}E_{0} \\
(\mathrm{GeV})\end{array}$ & $\begin{array}{c}E_{1} \\
(\mathrm{GeV})\end{array}$ & $\begin{array}{c}\mathrm{d} E / \mathrm{d} x \\
(\mathrm{keV} / \mathrm{nm})\end{array}$ & $\begin{array}{c}R_{\mathrm{p}} \\
(\mu \mathrm{m})\end{array}$ & $\begin{array}{c}\text { Fluence } \\
\left(\text { ions } / \mathrm{cm}^{2}\right)\end{array}$ & Pressure \\
\hline${ }^{238} \mathrm{U}$ & 2.71 & 2.64 & 34 & 83 & $1 \times 10^{10}$ & Vacuum \\
${ }^{238} \mathrm{U}$ & 2.71 & 2.64 & 34 & 83 & $5 \times 10^{10}$ & Vacuum \\
${ }^{238} \mathrm{U}$ & 2.71 & 2.64 & 34 & 83 & $1 \times 10^{11}$ & Vacuum \\
${ }^{238} \mathrm{U}$ & 2.71 & 2.64 & 34 & 83 & $5 \times 10^{11}$ & Vacuum \\
${ }^{238} \mathrm{U}$ & 2.71 & 2.64 & 34 & 83 & $1 \times 10^{12}$ & Vacuum \\
${ }^{238} \mathrm{U}$ & 2.71 & 2.64 & 34 & 83 & $8 \times 10^{12}$ & Vacuum \\
${ }^{84} \mathrm{Kr}$ & 8.90 & 2.10 & 6 & 238 & $5 \times 10^{11}$ & $10.5 \mathrm{GPa}$ \\
${ }^{84} \mathrm{Kr}$ & 9.25 & 2.10 & 6 & 238 & $5 \times 10^{11}$ & Ambient \\
\hline
\end{tabular}

TABLE 1 Compilation of essential irradiation parameters. $E_{0}$ denotes the initial kinetic energy of the ions as provided by the accelerator, $E_{1}$ and $\mathrm{d} E / \mathrm{d} x$ are the energy and the electronic energy loss of the ions at the sample surface, and $R_{\mathrm{p}}$ is the projected ion range in apatite radiated with $\mathrm{Kr}$ ions of initial energy $\sim 110 \mathrm{MeV} / \mathrm{u}$ available at the SIS heavy-ion synchrotron of GSI. The ions first passed through one of the two diamond anvils in which they slowed down from initially $8.9 \mathrm{GeV}$ to about $2.1 \mathrm{GeV}$ at the sample site. The fluence was $5 \times 10^{11}$ ions $/ \mathrm{cm}^{2}$, and the energy loss of the projectiles when entering the sample amounted to $\sim 6 \mathrm{keV} / \mathrm{nm}$. Further information about the irradiation procedure is given in $[12,15]$. As reference, a non-pressurized apatite sample mounted behind a single diamond anvil was irradiated in ambient air under the same fluence and energy loss conditions. Table 1 summarizes essential parameters of the irradiation experiments such as $\mathrm{d} E / \mathrm{d} x$ and the projected ion range $\left(R_{\mathrm{p}}\right)$ as calculated with the computer code SRIM 2003 [16].
Before and after beam exposure, the samples were characterized by Raman spectroscopy with a Jobin-Yvon HR800 confocal spectrometer using the 632.8-nm line of a $\mathrm{He}-\mathrm{Ne}$ laser in $180^{\circ}$ backscattering geometry. To study the sample pressurized in the DAC, the incident 20-mW laser beam was focused with a long-working-distance $\times 50$ objective to a diameter of approximately $2 \mu \mathrm{m}$, whereas for the other samples a diameter of $\sim 1 \mu \mathrm{m}$ was adjusted with a $\times 100$ objective. The scattered light was analyzed with a spectral precision of about $0.8 \mathrm{~cm}^{-1}$ using a grating of 1800 grooves $\mathrm{mm}^{-1}$. We applied a notch holographic filter and recorded the photon intensity with an air-cooled CCD detector. Intensities, positions, and widths of the Raman resonances were determined by fitting Lorentzians to the peaks.

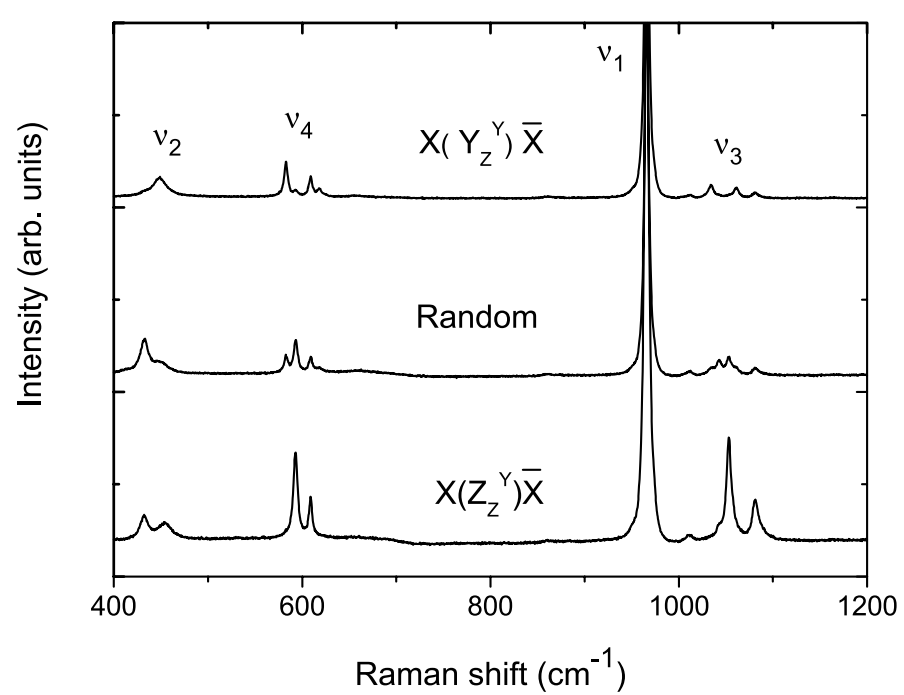

FIGURE 1 Raman spectra of an annealed but non-irradiated natural apatite single crystal recorded for three different crystal orientations with respect to the incident linearly polarized laser beam. The different bands are assigned to modes of the phosphate group: $v_{1}$ (symmetric stretching), $v_{2}$ (symmetric bending), $v_{3}$ (antisymmetric stretching), and $v_{4}$ (antisymmetric bending) 
3

\section{Results and discussion}

Before studying irradiated apatite, Raman spectra of non-irradiated samples were measured for calibration purposes in random and in $X\left(Y_{Z}^{Y}\right) \bar{X}$ and $X\left(Z_{Z}^{Y}\right) \bar{X}$ orientations. The expression $X\left(Y_{Z}^{Y}\right) \bar{X}$ denotes a geometry in which the incident laser beam is directed and the scattered light is recorded along the $X$ and $\bar{X}$ axes of the crystal, respectively. The incident laser light was linearly polarized, with the electric field vector parallel to the $Y$ axis. Figure 1 displays the three spectra and assignments of the $\mathrm{PO}_{4}$ internal modes. In $X\left(Y_{Z}^{Y}\right) \bar{X}$ geometry, all $A_{g}, E_{1 g}$, and $E_{2 g}$ Raman-active modes can be observed. In $X\left(Z_{Z}^{Y}\right) \bar{X}$ geometry, only the $A_{g}$ and $E_{1 g}$ modes occur, while $E_{2 g}$ is forbidden. Ramanactive vibrations can be attributed to the following phosphate modes: $964 \mathrm{~cm}^{-1}$ to the $v_{1}$ symmetric stretching vibration of phosphate anions, 430 and $453 \mathrm{~cm}^{-1}$ to the $v_{2}$ symmetric out-of-plane bending modes, 1052 and $1081 \mathrm{~cm}^{-1}$ to the $v_{3}$ antisymmetric stretching modes, and 591 and $608 \mathrm{~cm}^{-1}$ to $v_{4}$ antisymmetric bending [17-19]. All spectra presented in Sects. 3.1 and 3.2 were acquired in $X\left(Z_{Z}^{Y}\right) \bar{X}$ geometry.

\subsection{Irradiation of non-pressurized samples}

A series of apatite Raman spectra before and after the irradiation of single apatite crystals with $\mathrm{U}$ ions of various fluences (see Table 1) is shown in Fig. 2. The spectrum of nonirradiated apatite is dominated by the intense and relatively narrow $v_{1}\left(A_{g}\right)$ band centered at $964 \mathrm{~cm}^{-1}$ and as-

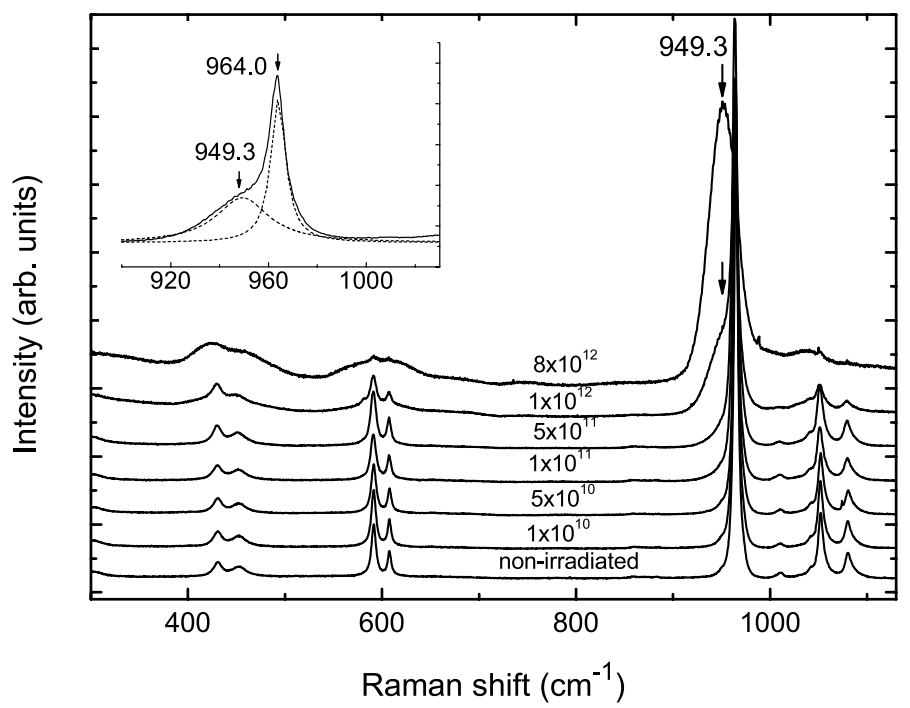

FIGURE 2 Raman spectra of a non-irradiated and of irradiated apatite samples. The irradiations were performed with 2.64-GeV U ions $(\mathrm{d} E / \mathrm{d} x=34 \mathrm{keV} / \mathrm{nm})$ at various fluences given in units of ions $/ \mathrm{cm}^{2}$. The inset shows the $v_{1}$ mode splitting at fluence $1 \times 10^{12}$ ions $/ \mathrm{cm}^{2}$. The linearly polarized laser light propagated normal to the crystallographic $c$ axis, with the electric field vector oscillating parallel to this axis

signed to the Raman-active $A_{g}$ mode. Further $A_{g}$ resonances appear at 450 , 608, 1052, and $1081 \mathrm{~cm}^{-1}$. The $E_{1 g}$ mode is at 430 and $591 \mathrm{~cm}^{-1}$. With increasing fluence, the positions, widths, and relative intensities of the different bands changed (Table 2). With respect to the non-irradiated sample, the changes are marginal for fluences up to $1 \times 10^{11}$ ions $/ \mathrm{cm}^{2}$. Above this value, the bands broadened, the crystals were strained, and at $5 \times 10^{11}$ ions $/ \mathrm{cm}^{2}$ cracked along planes normal to the $c$ axes (see Fig. 3). A sample irradiated with a fluence of $8 \times 10^{12}$ ions $/ \mathrm{cm}^{2}$ spontaneously decomposed into small pieces, but the remaining grains were still large enough to perform Raman spectroscopy.

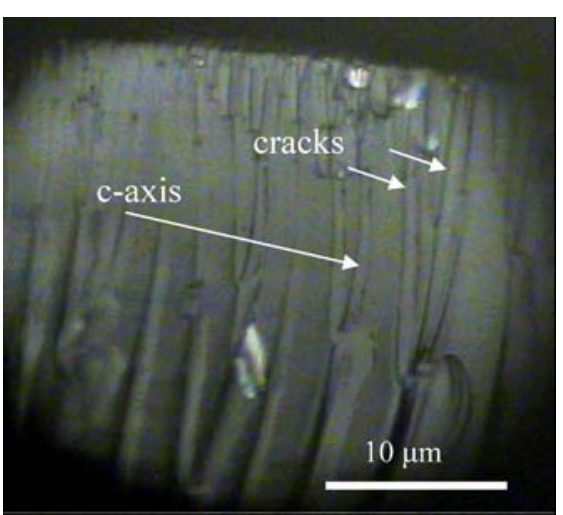

FIGURE 3 Optical micrograph of apatite sample irradiated with 2.64-GeV U ions of $\mathrm{d} E / \mathrm{d} x=$ $34 \mathrm{keV} / \mathrm{nm}$ at a fluence of $5 \times 10^{11}$ ions/ $\mathrm{cm}^{2}$. The beam incidence was normal to the surface. The arrows indicate cracks induced along the $c$ plane

\begin{tabular}{|c|c|c|c|c|c|c|c|c|c|c|c|c|c|c|c|c|c|c|c|c|c|c|c|}
\hline \multirow[t]{2}{*}{ Ion } & \multirow{2}{*}{$\begin{array}{l}\text { Press- } \\
\text { ure } \\
(\mathrm{GPa})\end{array}$} & \multirow{2}{*}{$\begin{array}{c}\text { Fluence } \\
\text { (ions/ } \\
\mathrm{cm}^{2} \text { ) }\end{array}$} & \multicolumn{3}{|c|}{$\begin{array}{c}v_{2 b}\left(E_{1 g}\right) \\
\left(430 \mathrm{~cm}^{-1}\right)\end{array}$} & \multicolumn{3}{|c|}{$\begin{array}{c}v_{2 b}\left(A_{g}\right) \\
\left(453 \mathrm{~cm}^{-1}\right)\end{array}$} & \multicolumn{3}{|c|}{$\begin{array}{c}v_{4 b}\left(E_{1 g}+A_{g}\right) \\
\left(591 \mathrm{~cm}^{-1}\right)\end{array}$} & \multicolumn{3}{|c|}{$\begin{array}{c}v_{4 a}\left(A_{g}\right) \\
\left(608 \mathrm{~cm}^{-1}\right)\end{array}$} & \multicolumn{3}{|c|}{$\begin{array}{c}v_{1}\left(A_{g}\right) \\
\left(964 \mathrm{~cm}^{-1}\right)\end{array}$} & \multicolumn{3}{|c|}{$\begin{array}{c}v_{3 b} A_{g} \\
\left(1052 \mathrm{~cm}^{-1}\right)\end{array}$} & \multicolumn{3}{|c|}{$\begin{array}{c}v_{3 a} A_{g} \\
\left(1081 \mathrm{~cm}^{-1}\right)\end{array}$} \\
\hline & & & $\begin{array}{c}\Delta v \\
\mathrm{~cm}^{-1}\end{array}$ & $\begin{array}{c}I / I_{0} \\
\%\end{array}$ & $\begin{array}{c}\Delta \Gamma \\
\mathrm{cm}^{-1}\end{array}$ & $\begin{array}{c}\Delta v \\
\mathrm{~cm}^{-1}\end{array}$ & $\begin{array}{c}I / I_{0} \\
\%\end{array}$ & $\begin{array}{c}\Delta \Gamma \\
\mathrm{cm}^{-1}\end{array}$ & $\begin{array}{c}\Delta v \\
\mathrm{~cm}^{-1}\end{array}$ & $\begin{array}{c}I / I_{0} \\
\%\end{array}$ & $\begin{array}{c}\Delta \Gamma \\
\mathrm{cm}^{-1}\end{array}$ & $\begin{array}{c}\Delta v \\
\mathrm{~cm}^{-1}\end{array}$ & $\begin{array}{c}I / I_{0} \\
\%\end{array}$ & $\begin{array}{c}\Delta \Gamma \\
\mathrm{cm}^{-1}\end{array}$ & $\begin{array}{c}\Delta v \\
\mathrm{~cm}^{-1}\end{array}$ & $\begin{array}{c}I / I_{0} \\
\%\end{array}$ & $\begin{array}{c}\Delta \Gamma \\
\mathrm{cm}^{-1}\end{array}$ & $\begin{array}{c}\Delta v \\
\mathrm{~cm}^{-1}\end{array}$ & $\begin{array}{c}I / I_{0} \\
\%\end{array}$ & $\begin{array}{c}\Delta \Gamma \\
\mathrm{cm}^{-1}\end{array}$ & $\begin{array}{c}\Delta v \\
\mathrm{~cm}^{-1}\end{array}$ & $\begin{array}{c}I / I_{0} \\
\%\end{array}$ & $\begin{array}{c}\Delta \Gamma \\
\mathrm{cm}^{-1}\end{array}$ \\
\hline \multirow[t]{6}{*}{$\mathrm{U}$} & - & 0 & 0 & & 0 & 0 & & 0 & 0 & & 0 & 0 & & 0 & 0 & & 0 & 0 & & 0 & 0 & & 0 \\
\hline & & $\times 10$ & -0.3 & 3.2 & 0.5 & -0.2 & 2.3 & -0.9 & -0.1 & 12.7 & 0.2 & -0.1 & 5.8 & 0.1 & -0.2 & 100 & 0.2 & -0.2 & & 0.1 & -0.2 & 5.7 & 0 \\
\hline & & & -0.1 & 3.3 & 0.7 & 0 & 2.1 & -1.6 & -0.1 & 11.5 & 0. & 0.1 & 5. & 0 & 0.1 & 100 & 0 . & 0.1 & 13 & 0 . & 0.2 & 5.2 & \\
\hline & & 11 & -0.5 & 3.3 & 1.2 & -0.5 & 2.5 & 0.9 & -0.4 & 11.5 & 1.2 & -0.2 & 5.7 & 0.7 & -0.8 & 100 & 0 . & -0.7 & 12 & 1. & -0.6 & 5.2 & 0 \\
\hline & & & -0.7 & 4.0 & 1.5 & -0.3 & 2.6 & 1.6 & -0.4 & 12.5 & 1.4 & -0.4 & 5.8 & 0.7 & -0.9 & 100 & 1.2 & -0.8 & 12.8 & 1.6 & -1.0 & 5.3 & -0 \\
\hline & & $1 \times 10^{12}$ & -1.8 & 8.7 & 18.1 & -2.9 & 3.8 & 2.3 & -0.7 & 12.7 & 6.8 & 0.3 & 6.3 & 2.3 & -1.4 & 100 & 2.5 & -3.6 & 9.0 & 6.1 & -1.3 & 5.7 & \\
\hline \multirow[t]{3}{*}{$\mathrm{Kr}$} & - & 0 & 0 & .1 & 0 & 0 & 2.2 & 0 & 0 & 11.9 & 0 & 0 & 5.0 & 0 & 0 & 100 & 0 & 0 & & 0 & 0 & 5.5 & 0 \\
\hline & 10.5 & م & -0.4 & .9 & 2.0 & -0.7 & 2.3 & -0.5 & -0.5 & 11.9 & 1.5 & -0.3 & 4.6 & 1.1 & -1.0 & 100 & & -1.1 & & 3. & -1.0 & 4.2 & \\
\hline & - & $5 \times 10^{11}$ & -0.9 & 3.2 & 2.0 & -1.4 & 2.7 & 3.5 & -1.5 & 13.0 & 2.5 & -1.4 & 6.0 & 1.3 & -1.3 & 100 & 1.5 & -0.8 & 13.7 & 1.9 & -0.8 & 5.6 & \\
\hline
\end{tabular}

TABLE 2 Characteristics of phosphate Raman modes for different irradiation parameters. $\Delta v$ is the frequency shift of the band, $\Delta \Gamma$ is the change of width, and $I / I_{0}$ denotes the ratio of a given band peak intensity to the most dominant band $v_{1}\left(A_{g}\right)$ at $964 \mathrm{~cm}^{-1}$ (symmetric stretching mode) 


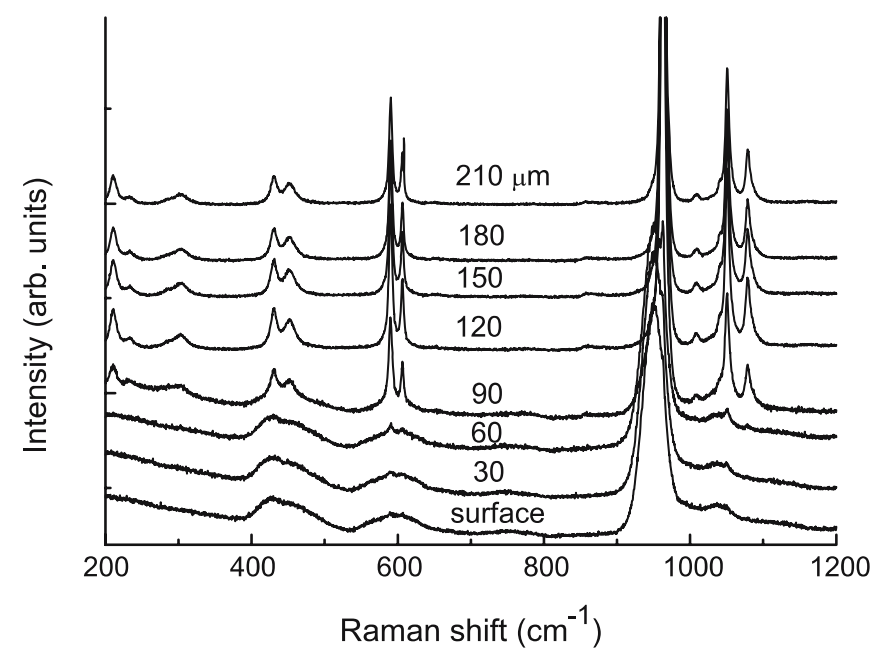

FIGURE 4 Raman spectra of apatite irradiated in vacuum with $2.64-\mathrm{GeV} U$ ions of $\mathrm{d} E / \mathrm{d} x=$ $34 \mathrm{keV} / \mathrm{nm}$ at a fluence of $8 \times 10^{12}$ ions $/ \mathrm{cm}^{2}$. The spectra were recorded successively by moving the laser focus from the surface into the bulk in steps of $30 \mu \mathrm{m}$ per spectrum. Thus, the second spectrum is taken at $30-\mu \mathrm{m}$ depth, the third at $60-\mu \mathrm{m}$ depth, and so on. The respective nominal focus depth is assigned to each spectrum

Compared to the non-irradiated sample, the position of the $v_{2 b}\left(E_{1 g}\right)$ band shifted after the irradiation with $1 \times 10^{12}$ ions $/ \mathrm{cm}^{2}$ from 430.7 to $428.9 \mathrm{~cm}^{-1}$ and its width increased from 10.1 to $28.2 \mathrm{~cm}^{-1}$. The strong $v_{1}\left(A_{g}\right)$ peak at $964 \mathrm{~cm}^{-1}$ became weaker and broader, and the relative intensities of $v_{2}, v_{3}$, and $v_{4}$ with respect to $v_{1}$ grew with increasing ion fluence except for $\nu_{3 b}\left(A_{g}\right)$. For instance, the relative intensity of the $v_{2 b}\left(E_{1 g}\right)$ peak changed from 3.1 to $8.7 \%$ and for the $v_{2 b}\left(A_{g}\right)$ peak from 2.2 to $3.8 \%$.

The spectrum of the sample exposed to $8 \times 10^{12}$ ions $/ \mathrm{cm}^{2}$ exhibits only broad features; the previously separated and sharp modes have disappeared. We note that at a fluence of around $1 \times 10^{12}$ ions $/ \mathrm{cm}^{2}$, a new $v_{1}\left(A_{g}\right)$ peak ascribed to phonons emerges at $949 \mathrm{~cm}^{-1}$ (see inset in Fig. 2), becoming pronounced at $8 \times 10^{12}$ ions $/ \mathrm{cm}^{2}$. The decrease of symmetric vibration modes is ascribed to increasing amorphization and thus distortion of the $\mathrm{PO}_{4}^{3-}$ tetrahedra. Assuming cylindrical amorphous tracks of diameter $10 \mathrm{~nm}$, the contribution of amorphized material in the irradiated layer of our samples is estimated to be $\sim 30 \%$ for $5 \times 10^{11}$ ions $/ \mathrm{cm}^{2}$. The amorphous fraction increases to $\sim 50 \%$ for $1 \times 10^{12}$ ions $/ \mathrm{cm}^{2}$ and, finally, the entire sample is expected to be amorphized at $8 \times 10^{12}$ ions $/ \mathrm{cm}^{2}$.

Figure 4 displays Raman spectra of a sample irradiated at the UNILAC with $2.64-\mathrm{GeV} \mathrm{U}$ ions of fluence
$8 \times 10^{12} \mathrm{ions} / \mathrm{cm}^{2}$. The spectra were recorded successively by changing the distance between sample surface and spectrometer objective in steps of $30 \mu \mathrm{m}$ per spectrum. The first four spectra down to a nominal depth of $90 \mu \mathrm{m}$ are similar to each other and differ significantly from the data recorded from deeper layers. The spectra were acquired without immersion liquid and thus the absolute depth of the focal plane is not well defined. However, within the given accuracy, the two different signals can be assigned to the irradiated surface layer and to the non-irradiated substrate layer, respectively, indicating that the

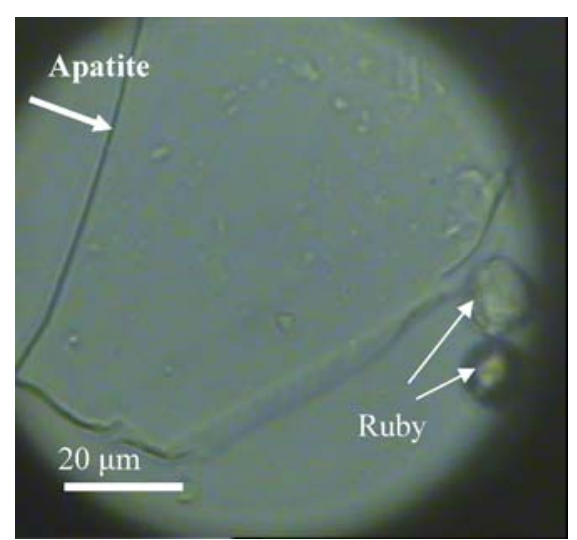

FIGURE 5 Optical micrograph of sample pressurized in a diamond anvil cell to $10.5 \mathrm{GPa}$ and irradiated with $2.1-\mathrm{GeV} \mathrm{Kr}$ ions $(\mathrm{d} E / \mathrm{d} x=$ $6 \mathrm{keV} / \mathrm{nm}$ ) at a fluence of $5 \times 10^{11} \mathrm{ions} / \mathrm{cm}^{2}$. The two ruby crystals on the right-hand side serve for pressure calibration by fluorescence measurement

sample crystallinity was changed within but remained unchanged beyond the ion range.

\subsection{Irradiation under high pressure}

A photograph of the smallsized apatite sample mounted in the DAC and pressurized to $10.5 \mathrm{GPa}$ is shown in Fig. 5. After irradiation with $\mathrm{Kr}$ ions of fluence $5 \times 10^{11} \mathrm{ion} / \mathrm{cm}^{-2}$ (Table 1), Raman spectroscopy of the pressurized sample was performed through the diamond of the DAC while releasing the pressure step by step to ambient conditions (Fig. 6). With decreasing pressure, all bands shift to

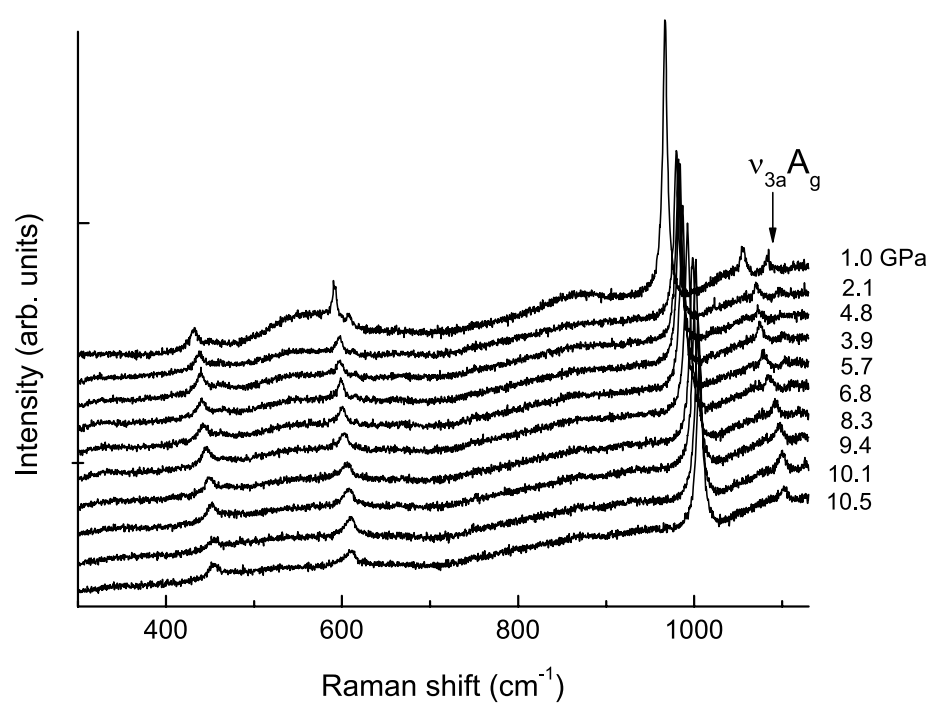

FIGURE 6 Raman spectra of apatite sample irradiated at $10.5 \mathrm{GPa}$ with $2.1-\mathrm{GeV} \mathrm{Kr}$ ions of $\mathrm{d} E / \mathrm{d} x=6 \mathrm{keV} / \mathrm{nm}$ at a fluence of $5 \times 10^{11}$ ions $/ \mathrm{cm}^{2}$. The spectra of the sample mounted in the DAC were recorded through one of the diamond anvils while releasing the pressure step by step 
smaller wavenumbers (see Table 2), e.g. the peak position of the $v_{1}\left(A_{g}\right)$ mode shifts from $1006 \mathrm{~cm}^{-1}$ at $10.5 \mathrm{GPa}$ to $964 \mathrm{~cm}^{-1}$ at ambient pressure. At $3.9 \mathrm{GPa}$, the second component of the $v_{3 a}\left(A_{g}\right)$ antisymmetric stretching mode appears at $1081 \mathrm{~cm}^{-1}$. For the Raman bands at $1052,964,591$, and $430 \mathrm{~cm}^{-1}$, the peak shifts with decreasing pressure are plotted in Fig. 7. Based on these results, the dimensionless Grüneisen parameter $\gamma_{i}$ of each mode was calculated by applying the equation

$\gamma_{i}=\left(\frac{\delta v_{i}}{\delta P}\right) \frac{K}{v_{i}}$,

where $v_{i}$ and $\delta v_{i}$ denote respectively the frequency and frequency shift of mode $i, \delta P$ is the pressure change, and $K$ is the bulk elasticity modulus amounting to $93 \mathrm{GPa}$ for apatite. The Grüneisen parameter describes the alteration of the vibration frequency in a crystal lattice due to increased or decreased lattice volume resulting from temperature or pressure changes. Using the slopes of the curves in Fig. 7, the $\gamma$ values of the $v_{2 b}\left(E_{1 g}\right), v_{4 b}\left(E_{1 g}+A_{g}\right)$, $v_{1}\left(A_{g}\right)$, and $\nu_{3 b}\left(A_{g}\right)$ Raman bands were calculated to be respectively $0.53,0.34$, 0.40 , and 0.44 , in agreement with results reported in the literature for phosphate modes of non-irradiated apatite [20].

In contrast to the sample irradiated at the UNILAC, none of the samples exposed to the higher energies exhibited cracks. This difference is ascribed to the fact that the UNILAC ions penetrate only about $80 \mu \mathrm{m}$ into the crystal and thus amorphize only a thin surface layer of the thick crystal, whereas the SIS ions have sufficiently high energy to pass completely through the sample.

Figure 8 depicts Raman spectra of a non-irradiated sample and of two samples irradiated with $5 \times 10^{11} \mathrm{~cm}^{-2}$ $\mathrm{Kr}$ ions of $2.1 \mathrm{GeV}$. One of the samples was pressurized to $10.5 \mathrm{GPa}$ during the irradiation; the other was exposed under the same conditions but at ambient pressure. The peak intensity ratio of $v_{2 b}\left(A_{g}\right)$ and $v_{1}\left(A_{g}\right)$ is $2.7,2.3$, and 2.2 for the non-irradiated sample and for the samples irradiated at $10.5 \mathrm{GPa}$ and at ambient conditions, respectively. Compared to the non-irradiated sample, the peak positions of the irradiated samples are shifted by $-0.7 \mathrm{~cm}^{-1}$ (irradiated at $10.5 \mathrm{GPa}$ ) and by $-1.4 \mathrm{~cm}^{-1}$

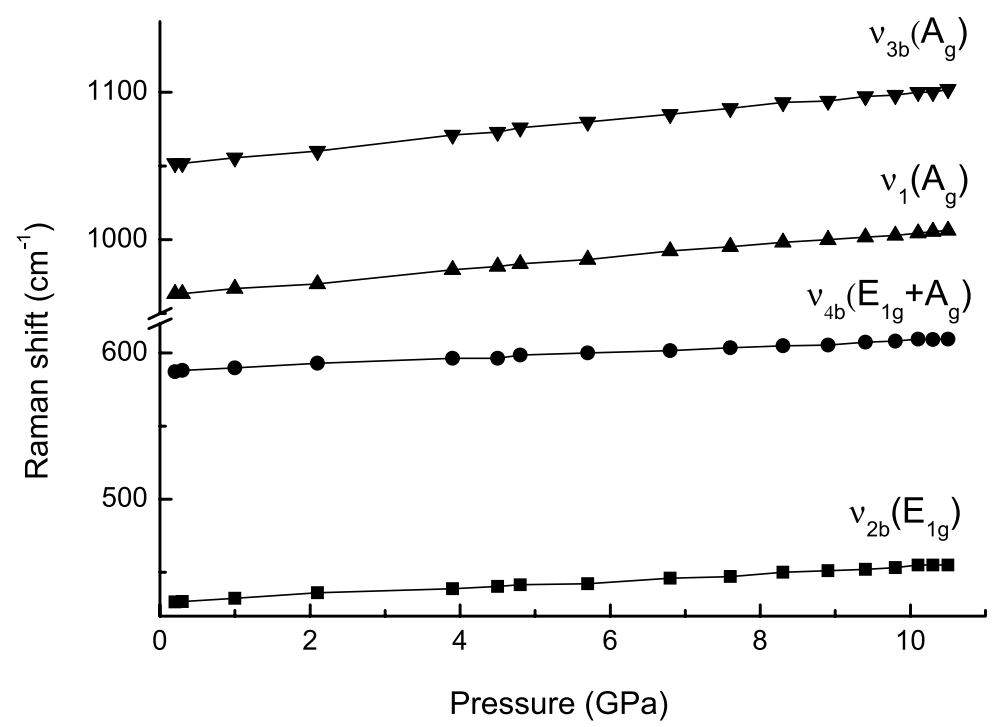

FIGURE 7 Positions of band maxima of the phosphate modes as a function of pressure deduced from Raman spectra shown in Fig. 6

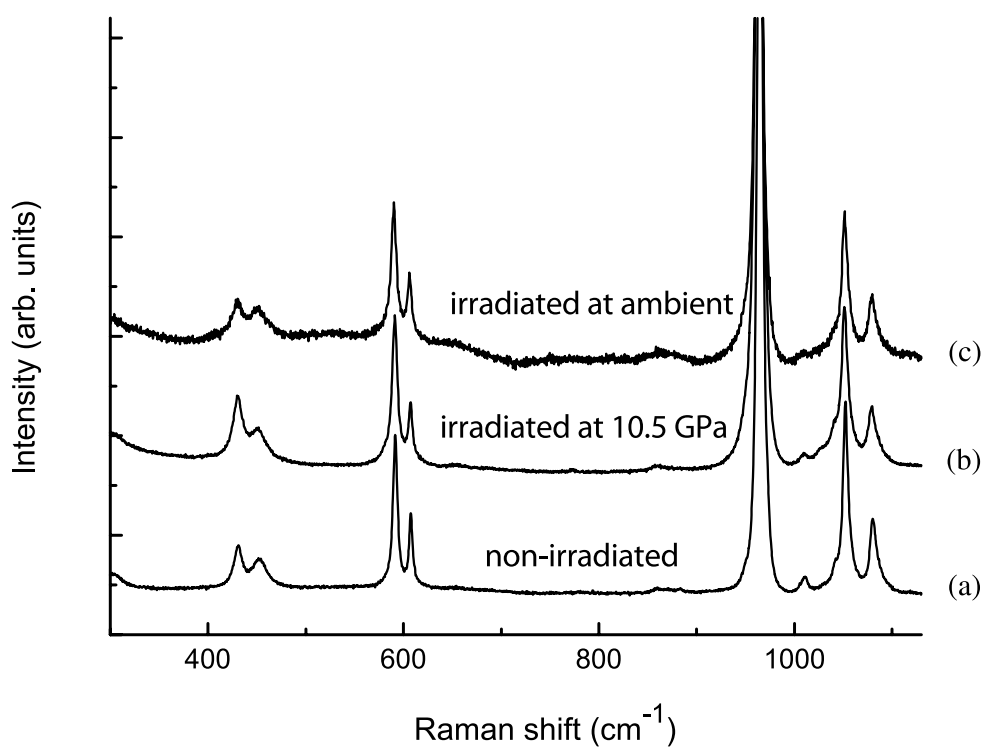

FIGURE 8 Raman spectra of (a) non-irradiated apatite and of samples irradiated with 2.1-GeV Kr ions of fluence $5 \times 10^{11}$ ions $/ \mathrm{cm}^{2}$ : (b) under pressure of $10.5 \mathrm{GPa}$ and (c) under ambient conditions. The Raman spectrum of (b) was recorded after pressure release

(irradiated at ambient conditions), indicating that beam exposure at ambient conditions causes more damage than under elevated pressure. It seems that the pressure strengthens the crystal lattice against damage from heavy-ion irradiation.

\section{Conclusion}

In summary, the analysis of Raman spectra demonstrates that apatite single crystals irradiated with swift heavy ions undergo structural changes. The effect is ascribed to the creation of amorphous tracks embedded in the crystalline matrix. The change of the vibrational modes is marginal at fluences below $5 \times 10^{11}$ ions $/ \mathrm{cm}^{2}$, but becomes considerable when increasing the fluence to $8 \times 10^{12}$ ions $/ \mathrm{cm}^{2}$. Concomitant significant strain is induced causing cracking and finally breakage of the crystal. This effect is in particularly strong in samples exposed to $2.7-\mathrm{GeV}$ $\mathrm{U}$ ions, which are stopped at a depth of $\sim 80 \mu \mathrm{m}$ and thus induce amorphization only in the thin irradiated surface layer on top of the underlying crystal. Comparing the Raman spectrum of the sample irradiated at $10.5 \mathrm{GPa}$ with the one exposed to an ion beam with the same 
parameters, but under ambient conditions, shows that fewer modifications are induced. This suggests that pressure increases the radiation stability of the lattice. This finding has to be examined by more systematic irradiation experiments at different pressures and using several ion species and fluences.

ACKNOWLEDGEMENTS J.L. gratefully acknowledges a one-year fellowship from the Max-Planck Society and the Max-Planck Institute of Nuclear Physics, Heidelberg. This project was partly supported by the National Natural Science Foundation of China (10775161).

\section{REFERENCES}

1 G.A. Wagner, E. Hejl, Chem. Geol. 87, 1 (1991)

2 C. Hepburn, A.H. Windle, J. Mater. Sci. 15, $279(1980)$
3 J.Y. Kim, Z.L. Dong, T.J. White, J. Am. Ceram. Soc. 88, 1253 (2005)

4 F. Villa, M. Grivet, M. Rebetez, C. Dubois, A. Chambaudet, N. Chevarier, G. Blondiaux, T. Sauvage, M. Toulemonde, Nucl. Instrum. Methods B 72, 168 (2000)

5 M. Grivet, M. Rebetez, A. Chambaudet, N. Ben Ghouma, Nucl. Tracks Radiat. Meas. 22, 779 (1993)

6 T.A. Paul, P.G. Fitzgerald, Am. Mineral. 77, $336(1992)$

7 M. Lang, Doctoral thesis, University of Heidelberg (2004)

8 G. Jaskierowicz, A. Dunlop, R. Jonckheere, Nucl. Instrum. Methods B 222, 213 (2004)

9 S. Miro, D. Grebille, D. Chateigner, D. Pelloquin, J.P. Stoquert, J.J. Grob, J.M. Costantini, F. Studer, Nucl. Instrum. Methods B 227, 306 (2005)

10 Q. Williams, E. Knittle, J. Phys. Chem. Solids 57, 417 (1996)

11 J.K. Murayama, M. Kato, S. Nakai, M. Kumazawa, Phys. Earth Planet. Interiors 44, 293 (1986)
12 U.A. Glasmacher, M. Lang, H. Keppler, F. Langenhorst, R. Neumann, D. Schardt, C. Trautmann, G.A. Wagner, Phys. Rev. Lett. 96, 195701 (2006)

13 L. Nasdala, P.W. Reiners, J.I. Garver, A.K. Kennedy, R.A. Stern, E. Balan, R. Wirth, Am. Mineral. 89, 219 (2004)

14 L. Nasdala, C.L. Lengauer, J.M. Hanchar, A. Kronz, R. Wirth, P. Blanc, A.K. Kennedy, A.-M. Seydoux-Guillaume, Chem. Geol. 191, 121 (2002)

15 M. Lang, U.A. Glasmacher, R. Neumann, D. Schardt, C. Trautmann, G.A. Wagner, Appl. Phys. A 80, 691 (2005)

16 J. Ziegler, J. Biersack, D. Marwick, SRIM2003: The Stopping and Range of Ions in Matter (IBM, New York, 2000)

17 L.C. Kravitz, J.D. Kingsley, E.L. Elkin, J. Chem. Phys. 49, 4600 (1968)

18 L.L. Boyer, P.A. Fleury, Phys. Rev. B 9, 2693 (1974)

19 M. Zattin, D. Bersani, A. Carter, Chem. Geol. 240, 197 (2007)

20 P. Comodi, Y. Liu, M.L. Frezzotti, Phys. Chem. Mineral. 28, 225 (2001) 